\title{
Teff, Buckwheat, Quinoa and Amaranth: Ancient Whole Grain Gluten-Free Egg-Free Pasta
}

\author{
Talwinder S. Kahlon, Mei-Chen M. Chiu \\ Western Regional Research Center, USDA-ARS, Healthy Processes Foods Research, Albany, USA \\ Email: Talwinder.Kahlon@ars.usda.gov
}

Received 16 July 2015; accepted 20 November 2015; published 23 November 2015

Copyright (C) 2015 by authors and Scientific Research Publishing Inc.

This work is licensed under the Creative Commons Attribution International License (CC BY). http://creativecommons.org/licenses/by/4.0/

(c) () Open Access

\section{Abstract}

This report demonstrates innovative ancient whole grains, gluten-free, egg-free pasta (no chemicals added) made using a kitchen counter-top appliance. Whole grain, fusilli pasta was prepared with teff, buckwheat, quinoa and amaranth flours. These ancient grains are called "Super Foods" due to their ideal essential amino acids and mineral profiles. Dough formulations contained $95 \%$ whole grain flour and $5 \%$ guar gum. Taste panels of 62 in-house volunteers judged amaranth pasta significantly $(p \leq 0.05)$ higher in color/appearance than other pastas tested. Odor/aroma of buckwheat pasta and texture/mouth-feel of teff pasta were significantly better than quinoa and amaranth pasta. Acceptance and taste/flavor of teff and buckwheat pasta were similar and significantly higher than quinoa and amaranth pasta (teff = buckwheat $>$ quinoa $>$ amaranth). The USDA food guide recommends that at least $1 / 2$ of all the grains eaten should be whole grains. The FDA allows food Health Claim labels for food containing $51 \%$ whole gains and $11 \mathrm{~g}$ of dietary fiber per serving. Novel health promoting whole grain, good source of protein, gluten-free, egg-free (no chemicals added) pasta had acceptance of teff $87 \%$, buckwheat $82 \%$, quinoa $61 \%$ and amaranth $\mathbf{1 5 \%}$. Amaranth pasta needs improvement in several sensory attributes by fortification, processing and/or use of other cultivars for the desired results. Ancient whole grain, gluten-free, egg-free pasta would increase whole grain consumption and offer a healthy option to vegetarians as well as to gluten sensitive individuals.

\section{Keywords}

Teff, Buckwheat, Quinoa, Amaranth, Ancient Grains, Gluten-Free Pasta 


\section{Introduction}

Pasta has been a staple food throughout the world over many centuries. Chinese invented pasta around 300 BCE. Greeks invented a spaghetti making device. Italians made dried pasta that made its way to the rest of Europe. The first industrial pasta factory in USA was built in Brooklyn, New York, in 1848. The top yearly per capita pasta consuming nations are Italy, 26 kg; Venezuela 13 kg, Tunisia, 12 kg; Greece 11 Kg; Switzerland, Sweden, USA and Iran 9 Kg; Chile, Peru, Argentina, Germany, France, Russia, Hungary and Uruguay 8 Kg. About 13.6 million tons of pasta is produced per year worldwide

http://www.internationalpasta.org/resources/World\%20Pasta\%20Industry\%20Survey/IPOstatreport2013.pdf [1]. Pasta comes in various shapes. Some of the common pasta are spaghetti (round-rod), ribbon cut noodles (fettuccini, lasagna) and short cut extruded (macroni, fusilli). In general, pasta dough is made by mixing durum wheat flour, water and eggs. In Italy, dried pasta made for domestic consumption must be made from durum wheat [2]. The restriction is partly a nod to tradition, but it's also a consequence of the practical and quality advantages that durum wheat imparts to pasta. The durum endosperm gives pasta a golden yellow color people associate with good quality pasta. In other countries some manufacturers use egg yolk to give the typical pasta color. High protein content (about 13\%), and gluten strength of durum provides pasta with consistent cooking quality and pleasing bite "al dente". With the increased prosperity in the developing nations like China, India and Brazil as well as changing demographics and ethnic character of the world population, various kinds of pasta are increasing in popularity. Most of the available pasta is made using refined wheat flour. USDA, Center for Nutrition Policy and Promotion; Dietary Guidelines for Americans, recommends that at least 50\% of all the grains eaten should be whole grains http://www.choosemyplate.gov/ [3]. It is recommended that whole grains should be used in making food products rather than refined grains. Whole Grain Council has summarized the scientific studies of the health benefits of whole grains http://www.wholegrainscouncil.org [4]. It has been documented that eating whole grains instead of refined grains lowers the risk of many chronic diseases. While benefits are most pronounced for those consuming at least 3 servings (48 g) daily, some studies show reduced risks from as little as one serving daily. US Food and Drug Administration (FDA) allows label health claim for food containing 51\% whole grains and $11 \mathrm{~g}$ of dietary fiber per serving

http://www.fda.gov/Food/LabelingNutrition/LabelClaims/FDAModernizationActFDAMAClaims/ucm073634.htm [5]. Wheat is the main grain of the pasta due to special properties of gluten. However there is increasing evidence of hyper-sensitivity to gluten in the celiac patients. Whole grain pasta would be desirable as refined grains are associated with an increasing number of type II diabetics. The FDA has published on August 1, 2013; a new regulate on defining the term "gluten-free" for voluntary food labeling

http://www.fda.gov/downloads/ForConsumers/ConsumerUpdates/UCM363276.pdf [6]. The FDA has set a gluten limit of less than 20 ppm (parts per million) in foods that carry the label "gluten-free, free of gluten, without gluten or no gluten”. This is the lowest level that can be consistently detected in foods using valid scientific analytical tools. This level is consistent with those set by other countries and international bodies that set food safety standards. Most people with celiac disease can tolerate foods with very small amounts (20 ppm) of gluten. It provides a uniform standard definition to help up to 3 million Americans who have celiac disease. The celiac disease is an autoimmune digestive condition that can be effectively managed only by eating a gluten-free diet. The celiac disease occurs when the body's natural defense system reacts to gluten by attacking the lining of the small intestine. Without a healthy intestinal lining, the body cannot absorb the nutrients it needs. Delayed growth and nutrient deficiencies can result and may lead to conditions such as anemia and osteoporosis. Other serious health problems may include diabetes, autoimmune thyroid disease and intestinal cancers. Before the FDA rule there were no federal standards or definitions for the food industry to use in labeling products "glutenfree”. An estimated 5\% of foods currently labeled "gluten-free” contain higher than 20 ppm of gluten. Gluten hypersensitivity has been increasing in the world. Some of the potential reasons could be that microbial transaminase enzyme has been used as animal protein glue to produce meat patties from meat scraps. Transamination of gluten could make it hypersensitive. Other reasons could that the dwarf high yielding wheat varieties have gibberellin-gene silenced, resulting in dwarf wheat varieties with reduced chance of lodging and higher grain yield. It may have unintended consequence of gluten with higher allergenicity. The potential reason may be that some people have lost gluten immunity due to polluted toxic environment and/or change in gut microbiome. Working with gluten-free flours, some of the gluten strength could be attained with agar, guar gum, konjac, locust bean gum, sodium alginate, tara gum, xanthan, modified starches or other hydrocolloids. In USA, FDA al- 
lows up to $2 \%$ concentrated glycerol monostearate in macaroni and $3 \%$ in noodles, as an emulsifier which improves texture and reduces stickiness.

Previously reported acceptance of whole grain gluten-free egg-free fusilli pasta has been corn $83 \%$, sorghum $79 \%$, brown rice $77 \%$ and millet $50 \%$ [7]. The acceptance of whole grain gluten-free egg-free high protein fusilli pasta have been observed for corn-garbanzo $70 \%$, sorghum-garbanzo $48 \%$, brown rice-garbanzo $84 \%$ and millet-garbanzo 54\% [8].

There is increasing interest in the gluten-free ancient grains. The study reported herein whole grain glutenfree, egg-free teff, buckwheat, quinoa and amaranth fusilli pasta was formulated and evaluated by 62 in-house volunteer tasters. These ancient grains are called "Super Foods" due to their ideal essential amino acids and mineral profiles. The object was to offer every household (or a commercial production) the choice to make fresh or dry ancient whole grain, gluten-free, egg-free (no chemical added) pasta using a kitchen counter-top appliance in order to offer a low cost healthy staple food. It would increase ancient whole grain consumption, and offer a healthy nutritious option to vegetarians and gluten sensitive individuals.

\section{History of Ancient Gluten-Free Whole Grains}

\subsection{Teff}

Teff is an ancient grain native to the northern Ethiopian Highlands and Eritrean Highlands of Horn of Africa http://foodtank.com/news/2014/02/indigenous-crop-ancient-crop-with-modern-potential [9]. Teff is an annual cereal grain that can be cultivated in a wide range of conditions, from marginal soils to drought conditions. Teff is an important food grain of Ethiopia to make flatbread injera or tayta. Teff grain (Figure 1) is tiny when compared to wheat; it takes 150 grains of teff to be equal one kernel of wheat. Teff 3000 grains weigh just about one gram. Teff is an excellent source of protein, amino acids and fiber. Two ounce $(56 \mathrm{~g})$ serving of teff has $8 \mathrm{~g}$ of protein, compared to a large egg that contains $6 \mathrm{~g}$ of protein. Teff is higher in calcium and iron content than wheat, rice, oats or millet.

\subsection{Buckwheat}

Buckwheat is a pseudocereal, it is related to rhubarb, knotweed and sorrel (Figure 1). Its grain has unique triangular shape with size similar to wheat kernels. The United States was the world's fifth largest producer of

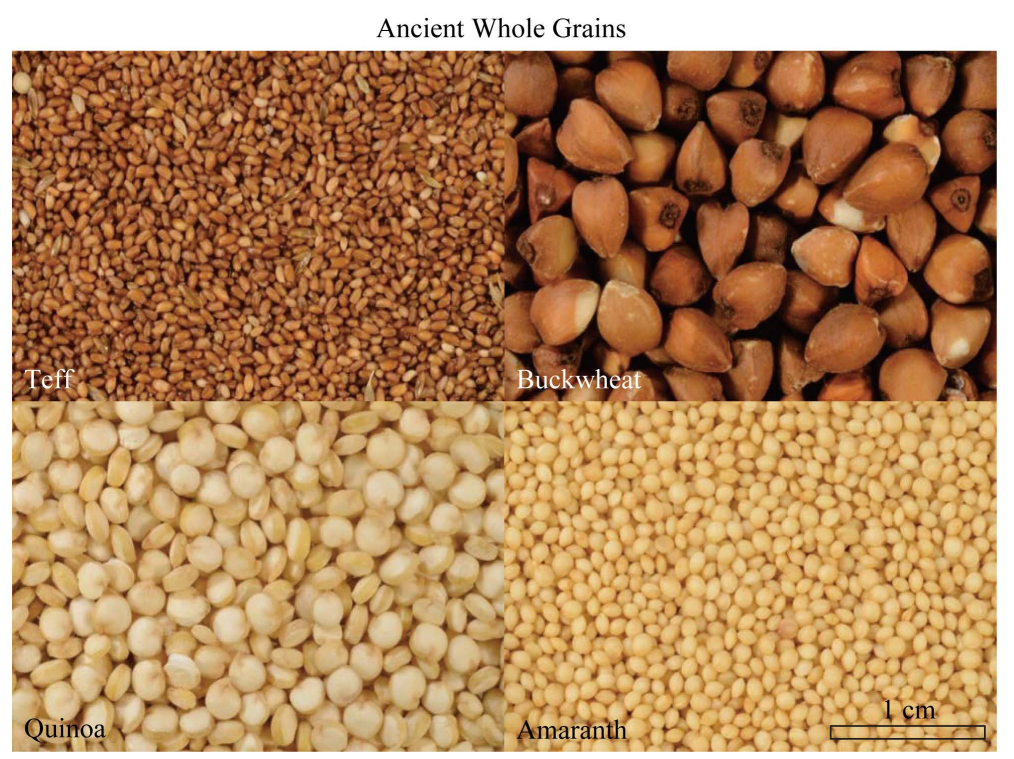

Figure 1. Ancient Gluten-Free Whole grains, Teff (top left), Buckwheat (top right), Quinoa (bottom left), and Amaranth (bottom right). Number of grains weigh about one gram, Teff 3000, Buckwheat 25, Quinoa 250 and Amaranth 1500 . 
buckwheat in 2011. China and Russia was the leading producer that year, followed by Eukraine and Polland [10]. Buckwheat is a low input crop with relatively high yields, even in marginal soil. Buckwheat grows quickly. Its 30-day maturity rate allows it to kill off most weeds that would compete for its resources. Buckwheat 25 grains weigh about one gram.

\subsection{Quinoa}

The history of quinoa is rooted in South America, in the Andes region that is currently divided up between the countries of Argentina, Bolivia, Chile, Columbia, Ecuador, and Peru. Along with maize, quinoa was one of the two mainstay foods for the Inca Empire that had its start around 1200 AD. Protein of quinoa is considered perfect food as it contains all the nine essential amino acids. The Food and Agricultural Organization of the United Nations (FAO), Press Release Note No. 6367, 24 October 2012 officially declared that the year 2013 be recognized as "The International Year of the Quinoa" http://www.un.org/News/Press/docs/2012/note6367.doc.htm [11]. Peru and Bolivia produce over 71,000 metric tons of quinoa. Quinoa grain is round disc shaped. Quinoa grain (Figure 1) resembles sorghum and it can be cooked as rice. 250 Quinoa grains weigh about one gram.

\subsection{Amaranth}

Amaranth was first used as a grain crop over 6,000 years ago in Central America and is gaining popularity now among health-conscious consumers http://eap.mcgill.ca/CPC 9.htm [12]. Amaranth grain (Figure 1) is high in lysine and fiber, well balanced in other amino acids. Amaranth 1500 grains weigh about one gram. In Mexico popped amaranth grain is mixed with honey to make candy "alegria”. In North India, popped amaranth is mixed with melted jiggery to make "laddoos" called "rājgeerā".

\section{Advantages of Ancient Whole Grain, Gluten-Free, High Protein, Egg-Free Pasta}

The ancient whole grain gluten-free fusilli pasta reported herein offer healthy choices to all consumers and especially to vegetarian and those with sensitivity to gluten. These ancient grains are called "Super Foods" due to their ideal essential amino acids and mineral profiles. Whole grain pasta is made with $100 \%$ extraction flours containing all the healthful phytonutrients of bran and germ. They are good source of protein, dietary fiber, and minerals and contain all the benefits of phytonutrients contained in the bran portion of the grains. The formulations of the pasta are simple for any household or commercial production as they contain only a few ingredients. They are excellent side dish to be served with curries, sauces, soups, vegetables and meat dishes. The preparation is simple for any home to make fresh or dry ancient whole grain, gluten-free, egg-free pasta using counter-top kitchen appliances. Cooking with $2 \mathrm{~g}$ salt in 2 quarts of water keeps pasta low in salt content. Spices and condiments could be incorporated into pasta dough. Cooking pasta while drying would result in healthy whole grain, a good source of protein and dietary fiber snacks.

\section{Methods and Materials}

Ancient whole-grains and flours of quinoa, teff, amaranth, buckwheat and guar gum were purchased from local markets. Ancient gluten-free whole grains, Quinoa, Teff, Amaranth and Buckwheat are shown (Figure 1).

\subsection{Composition of Ancient Gluten-Free Grains}

The composition of the ancient whole grain, gluten-free flours is listed in Table 1. Samples were analyzed for nitrogen, using AOAC method 990.03 [13] and an elemental analyzer (Virio Macro, Elementar Analysen Systeme GmbH); total dietary fiber, using AOAC method 985.29 [13] for crude fat with petroleum ether and an accelerated solvent extractor (ASE 350, Dionex Corp.; ash, using AOAC method 942.05 [14]; and moisture, using AOAC method 935.29 [14].

\subsection{Formulation}

The ancient whole grain, gluten-free, egg-free (no chemicals added) pasta dough formulations are given in Table 2. Dry ingredients were mixed in a bowl of a kitchen counter-top appliance (KitchenAid Proline, St. Joseph, 
Table 1. Composition of ancient whole grain gluten-free flours (DM) basis, \%.

\begin{tabular}{cccccccc}
\hline Ingredient & Protein & Fat & Minerals & Carbohydrate & TDF & DM & 89.71 \\
Teff & 13.81 & 3.73 & 2.86 & 79.60 & 79.45 & 11.25 & 88.85 \\
Buckwheat & 14.20 & 3.49 & 2.86 & 74.15 & 8.51 & 89.25 \\
Quinoa & 16.46 & 6.01 & 3.38 & 72.73 & 8.81 & 90.31 \\
Amaranth & 17.16 & 7.37 & 2.74 & & \\
\hline
\end{tabular}

Nitrogen to protein factors used was 6.25. Total Dietary Fiber, TDF; Dry matter, DM. Car-bohydrate $=[100-($ Protein + Fat + Ash $)]$.

Table 2. Formulation of ancient whole grain high protein fusilli pasta dough.

\begin{tabular}{ccccc}
\hline \multirow{2}{*}{ Whole Grain } & Cereal & Guar gum & Water & Cooking Time \\
\cline { 2 - 5 } & Flour, g & $\mathrm{g}$ & $\mathrm{mL}$ & Minutes \\
\hline Teff & 475 & 25 & 350 & 6 \\
Buckwheat & 475 & 25 & 300 & 6 \\
Quinoa & 475 & 25 & 350 & 6 \\
Amaranth & 475 & 25 & 325 & 6 \\
\hline
\end{tabular}

MI). Water was added slowly to form pasta dough. Pasta dough was covered and held at room temperature for 30 min. Pasta dough may be stored at refrigerator temperature overnight. Pasta was extruded using a pasta press (KitchenAid attachment). Pasta dough was slowly fed in small portions into the press. Various shapes of pasta (Spaghetti, Bucatini, small and large Macaroni, Rigatoni and Fusilli) were tried. Desired results were obtained with Fusilli as the pasta maintained its shape after cutting with the swing-arm cutter of the pasta press. Fusilli pasta was cut about 1.5 inch length and placed in a single layer over cheese cloth on drying trays of a food dehydrator (Excalibur Products ParallexX) at $135^{\circ} \mathrm{F}$ for $3 \mathrm{hr}$. In rural households pasta could be made with hand operated press and sun dried. Figure 2 shows uncooked (Raw, dry) ancient gluten-free whole grains pasta, Teff (top left), Buckwheat (top right), Quinoa (bottom left) and Amaranth (bottom right). Dried pasta was stored in zipped plastic bags. Dry pasta (100 g) was cooked in two quarts of boiling water with 2 g added salt. The pasta was cooked for 6 min as desired. Cooking time was determined with the consensus of laboratory personnel. 100 g dry pasta made about 4 cups of cooked pasta.

Figure 3 shows cooked ancient gluten-free whole grains pasta, Teff (top left), Buckwheat (top right), Quinoa (bottom left) and Amaranth (bottom right).

In-house 62 taste panelists evaluated all four kinds of cooked pasta. The tasters were offered cooked pasta (3 pieces each) on a tray labeled Teff, A; Buckwheat, B; Quinoa, C; and Amaranth, D; along with generic pasta sauce in a small cup. In the individual booths with white light tasters were offered all appropriately labeled test samples in a tray. The tasters evaluated the whole grain, gluten-free, egg-free (no chemicals added), low salt pasta for color/appearance, odor/aroma, taste/flavor, and texture/mouth-feel on a scale of 1 - 5 (like very much = 5 , like slightly $=4$, neutral $=3$, dislike slightly $=2$, dislike very much $=1$ ). The overall acceptable preference was on a scale of $1-2$ (acceptable $=2$, not acceptable $=1$ ).

\section{Results and Discussion}

Ancient whole grain, gluten-free, egg-free (no chemicals added), fusilli pasta was evaluated by 62 in-house volunteers (Table 3). Whole grain amaranth pasta was judged significantly $(\mathrm{P} \leq 0.05)$ higher in Color/Appearance than teff, buckwheat and quinoa pasta. Data suggest that creamy yellow color was preferred over other colors of pasta tested. For odor/aroma, taste/flavor, texture/mouth feel and acceptance of buckwheat and teff pasta was similar. These sensory values for amaranth pasta were significantly lower than other three pastas tested. Data suggest that strong after taste of amaranth pasta resulted in its lower sensory evaluation. The acceptance for ancient whole grain gluten-free, egg-free pasta was teff $87 \%$, buckwheat $82 \%$, quinoa $61 \%$ and amaranth $15 \%$ (Figure 4). Acceptance values for ancient grain pasta were teff = buckwheat $>$ teff $>$ amaranth. The acceptance 


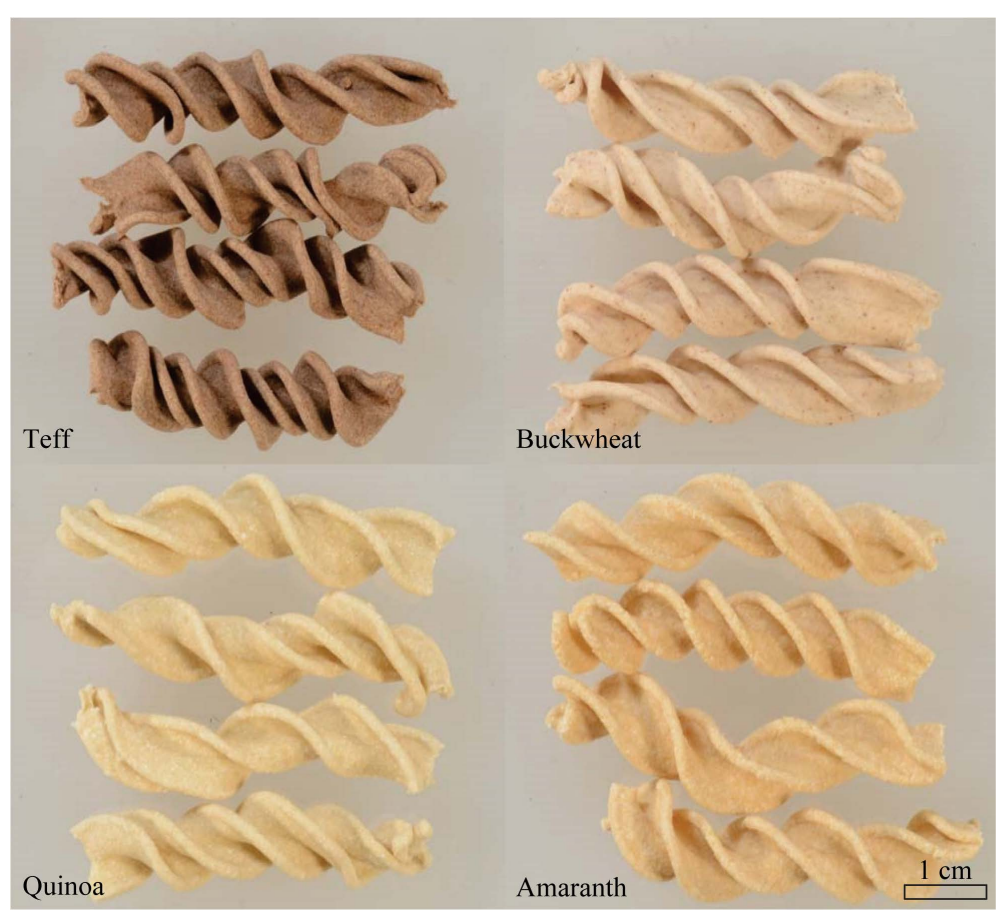

Figure 2. Died (Raw) ancient gluten-free whole grains pasta, Teff (top left), Buckwheat (top right), Quinoa (bottom left), and Amaranth (bottom right).

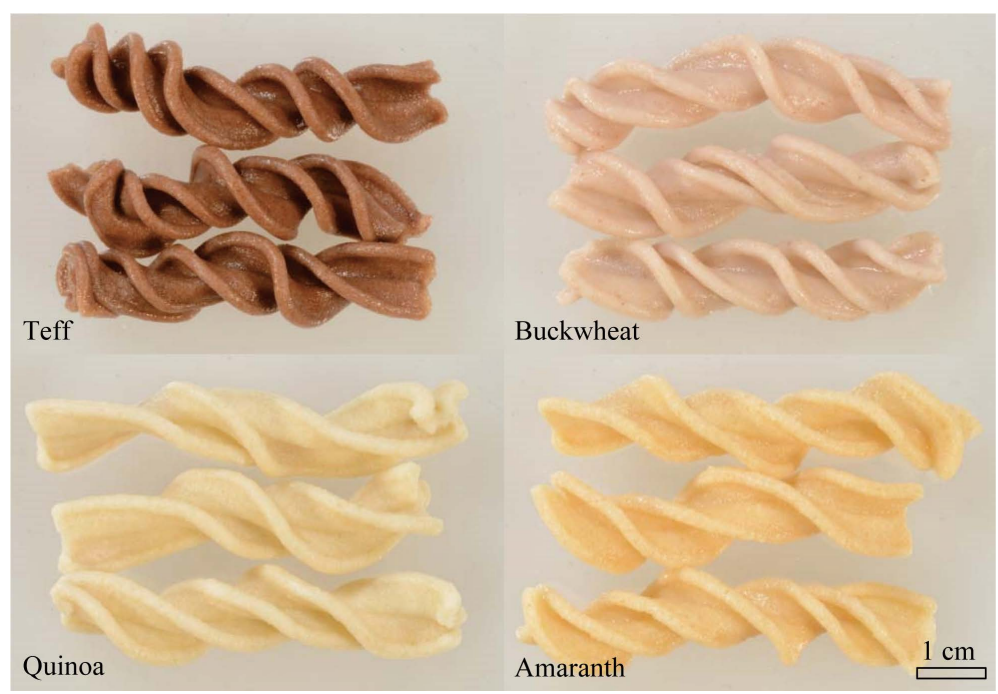

Figure 3. Cooked Ancient Gluten-Free Whole grains pasta, Teff (top left), Buckwheat (top right), Quinoa (bottom left), and Amaranth (bottom right). $100 \mathrm{~g}$ pasta was cooked in $2 \mathrm{~L}$ boiling water containing $2 \mathrm{~g}$ salt for 6 minutes and strained.

of teff, buckwheat and quinoa pasta would be considered desirable. However amaranth pasta needs improvement in sensory attributes by fortification, processing and/or use of other cultivars. Previously Kahlon et al. [15] reported that $66 \%$ - 84\% acceptability of flatbreads of quinoa, teff and amaranth, where values for buckwheat were $38 \%$. In this study acceptability of buckwheat pasta is $82 \%$. In the study reported herein for buckwheat contained no hulls, whereas flatbread study buckwheat contained nearly $20 \%$ hulls resulting in chocolate brown color buckwheat flour with gritty mouth feel that resulted in lower acceptance. The desirability index was calculated (Desirable index $=[$ like very much $]+[$ like slightly $]+[($ neutral/2)] $)$ as reported previously [7] [8]. Desirability index for 
Table 3. Results of taste panel of ancient whole grain, gluten-free fusilli pasta ${ }^{\text {abc }}$.

\begin{tabular}{cccccc}
\hline Whole Grain & Color/Appearance & Odor/Aroma & Taste/Flavor & Texture/Mouth-feel & Acceptance \\
\hline Teff & $3.65 \pm 0.15^{\mathrm{b}}$ & $3.61 \pm 0.12^{\mathrm{ab}}$ & $3.97 \pm 0.12^{\mathrm{a}}$ & $3.97 \pm 0.13^{\mathrm{a}}$ & $1.87 \pm 0.04^{\mathrm{a}}$ \\
Buckwheat & $3.45 \pm 0.12^{\mathrm{b}}$ & $3.77 \pm 0.11^{\mathrm{a}}$ & $3.79 \pm 0.12^{\mathrm{a}}$ & $3.68 \pm 0.14^{\mathrm{ab}}$ & $1.82 \pm 0.05^{\mathrm{a}}$ \\
Quinoa & $3.55 \pm 0.12^{\mathrm{b}}$ & $3.32 \pm 0.17^{\mathrm{b}}$ & $3.15 \pm 0.16^{\mathrm{b}}$ & $3.45 \pm 0.14^{\mathrm{b}}$ & $1.61 \pm 0.06^{\mathrm{b}}$ \\
Amaranth & $4.07 \pm 0.10^{\mathrm{a}}$ & $2.95 \pm 0.14^{\mathrm{c}}$ & $2.58 \pm 0.13^{\mathrm{c}}$ & $1.90 \pm 0.13^{\mathrm{c}}$ & $1.15 \pm 0.05^{\mathrm{c}}$ \\
\hline
\end{tabular}

${ }^{\mathrm{a}}$ Values are mean \pm SEM; $\mathrm{n}=62$; ${ }^{\mathrm{b} C o l o r} /$ Appearance, Odor/Aroma, Taste/Flavor, and Texture/Mouth feel were on a scale of $1-5$ (Like very much = 5 , like slightly $=4$, neutral $=3$, dislike slightly $=2$ and dislike very much $=1$ ); Acceptance was on scale of 1-2 (Acceptable $=2$ and unacceptable $=1$ ); ${ }^{c}$ Values within columns with different superscript letters differ significantly $(\mathrm{P} \leq 0.05)$.

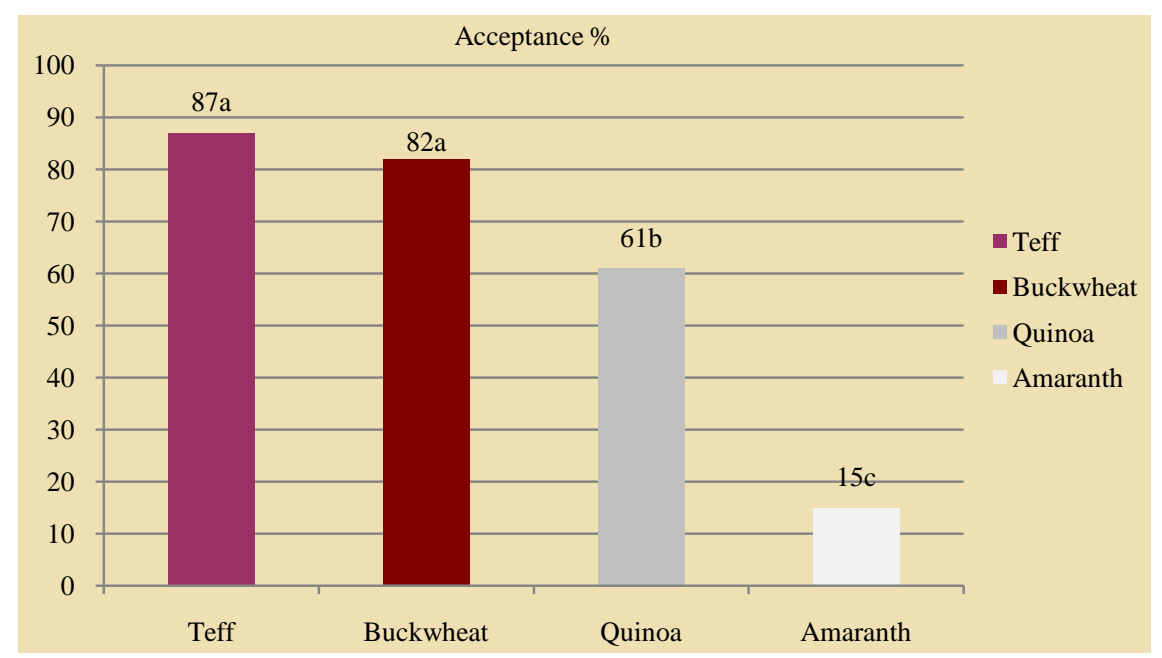

Figure 4. Panelist overall acceptance (\%) for ancient whole grain, gluten-free, egg-free, no chemicals added, Teff, Buckwheat, Quinoa and amarath fusilli pasta, $n=62$. Bars with different letters differ significantly $(\mathrm{P} \leq 0.05)$.

teff, buckwheat and amaranth gluten-free, egg-free (no chemicals added) pasta was for color/appearance (66\%, $70 \%, 71 \%$, 88\%), for odor/aroma $(77 \%, 72 \%, 59 \%$, $49 \%)$, for taste/flavor $(77 \%, 83 \%, 52 \%$, 35\%), for texture/mouth feel $(73 \%, 81 \%, 65 \%, 15 \%)$ respectively. The color/appearance and odor/aroma were quite desirable for the four ancient gain pastas tested. Data suggest that it was taste/flavor and texture/mouth feel for amaranth pasta needs improving by fortification, processing and/or exploring other cultivars. $100 \mathrm{~g}$ dry ancient grain pasta would make four cups of cooked pasta with $14-17 \mathrm{~g}$ of protein and 8 - $11 \mathrm{~g}$ of dietary fiber.

\section{Conclusion}

The ancient whole grain, gluten-free, egg-free (no chemicals added) pasta is nutritious, easy to make at home or in any commercial production. It could be an everyday staple food for all families. It is low in fat, and calories, and is a good source of protein, dietary fiber and minerals. Taste panel of 62 in-house volunteers determined that for amaranth pasta color/appearance was only significantly preferred than other three pastas tested. However, all the other sensory parameters for amaranth pasta were judged as significantly lower than teff, buckwheat and quinoa pasta. Taste/flavor and acceptance teff and buckwheat pasta were similar and significantly higher than quinoa pasta. Amaranth pasta sensory characteristics need to be improved by fortification, processing and/or used of other cultivars. Acceptance for teff, buckwheat and quinoa pasta would be considered desirable $61 \%$ $87 \%$. These ancient whole grains, gluten-free, egg-free pastas would increase whole grain consumption and offer a healthy option to vegetarians and to those with sensitivity to gluten.

\section{References}

[1] (2013) International Pasta Organization Survey. 
http://www.internationalpasta.org/resources/World\%20Pasta\%20Industry\%20Survey/IPOstatreport2013.pdf

[2] Decker, K.J. (2012) Shape of Things to Come: Innovations in Pasta. Food Products Design. http://www.foodproductdesign.com/articles/2012/01/shape-of-things-to-come-innovations-in-pasta.aspx

[3] (2010) USDA, Center for Nutrition Policy and Promotion; Dietary Guidelines for Americans. http://www.choosemyplate.gov/

[4] (2009) Whole Grain Council. http://www.wholegrainscouncil.org/

[5] (2003) US Food and Drug Administration. http://www.fda.gov/Food/LabelingNutrition/LabelClaims/FDAModernizationActFDAMAClaims/ucm073634.htm

[6] (2013) US Food and Drug Administration, Consumer Health Information. http://www.fda.gov/downloads/ForConsumers/ConsumerUpdates/UCM363276.pdf

[7] Kahlon, T.S., Milczarek, R.R. and Chiu, M.M. (2013) Whole Grain Gluten-Free Egg-Free Pasta. Cereal Foods World, 58, 4-7. http://dx.doi.org/10.1094/CFW-58-1-0004

[8] Kahlon, T.S., Milczarek, R.R. and Chiu, M.M. (2013) Whole Grain Gluten-Free Egg-Free High Protein Pasta. Vegetos, 26, 65-71. http://dx.doi.org/10.5958/j.2229-4473.26.2.055

[9] (2014) Indigenous Crop: Teff-Ancient Crop with Modern Potential. http://foodtank.com/news/2014/02/indigenous-crop-ancient-crop-with-modern-potential

[10] Vera Popovic, V., Sikora, V., Berenji, J., Filipovic, V., Dolijanovic, Z., Ikanovic, J. and Doncic, D. (2014) Analysis of Buckwheat Production in the World and Serbia. Ekonomika Poljoprivrede, 1, 52-63. http://dx.doi.org/10.5937/ekopolj1401053p

[11] (2012) Food and Agricultural Organization of the United Nations. http://www.un.org/News/Press/docs/2012/note6367.doc.htm

[12] Whiteman-Jones, M. (1991) Modern Market Rediscovers Ancient Grains. http://eap.mcgill.ca/CPC_9.htm

[13] AOAC (2000) Official Methods of Analysis of the Association of Official Analytical Chemists. 17th Edition, The Association, Arlington.

[14] AOAC (1990) Official Methods of Analysis of the Association of Official Analytical Chemists. 15th Edition, The Association, Arlington.

[15] Kahlon, T.S. and Chiu, M.M. (2014) Ancient Whole Grain Gluten-Free Flatbreads. Food and Nutrition Sciences, 5, 1717-1724. http://dx.doi.org/10.4236/fns.2014.517185 